\title{
Отражение революционных событий 1905 года в рассказе Л. Н. Андреева «Губернатор"
}

\section{Reflection of the Revolutionary Events of 1905 in the Short Story "The Governor" by L. N. Andreyev}

Юлия Алексеевна Дмитриева

(Брно, Чехия)

\section{Абстракт:}

Статья посвящена изучению рассказа Л. Н. Андреева «Губернатор» и отображения в нем революционных событий 1905 года. Писатель не воспроизводит исторические факты с предельной точностью, но произведенный анализ рассказа позволяет предположить, что он явился откликом Андреева на «Кровавое воскресенье» и последующее убийство московского генерал-губернатора Сергея Александровича. Но как и во многих произведениях Андреева, описанное в данном рассказе происшествие второстепенно и в большей степени является переломным моментом, сильно повлиявшим на главного героя. Губернатор, являющийся частью бюрократической машины, проходит сложнейший путь осознания своего бесчеловечного приказа о расстреле людей, что не являлось, по мнению героя, государственной необходимостью. Андреев в рассказе освещает вопросы роли человека в ходе исторических событий, его способности или неспособности в проявлении сострадания и человечности, руководствуясь не логикой власти, а общечеловеческими моральными ценностями.

\section{Ключевые слова:}

Леонид Андреев; «Губернатор»; революция; событие; человечность; личность

1 Статья разработана в рамках проекта специфического исследования Философского факультета Университета имени Масарика Брно MUNI/A/1331/2020 «Mezislovanské kulturní a literární vazby». 


\section{Abstract:}

The article is devoted to the study of the story of L. N. Andreyev "The Governor" and selected revolutionary events of 1905 . The writer does not reproduce historical facts with utmost precision, but the analysis of the story suggests that it was Andreev's response to Bloody Sunday and the subsequent murder of Moscow's governor-general Sergei Alexandrovich. But as in many works by Andreyev, the incident described in this story is secondary and becomes a turning point that has greatly influenced the main hero. The governor, who is part of the bureaucratic machine, passes the most difficult way to realize his inhuman order to shoot people, which, according to the hero, was not a state of necessity. Andreyev in the story highlights the role of man in the course of historical of events, his ability or inability to show compassion and humanity, his will to be guided not by the logic of power, but by the moral values.

\section{Key words:}

Leonid Andreyev; "The Governor”; revolution; events; humanity; personality

Революционные события, потрясшие Россию в начале 20 века, повлияли на все сферы жизни российского общества, в том числе и на его культурную сторону. Литературный процесс старался отобразить реальное противоборство социальных и классовых сил, идеологических течений и, в свою очередь, формировал общественное мнение. Тема революции, как и многих других писателей, не обошла стороной и Л. Н. Андреева. Известный критик М. П. Неведомский писал в журнале «Современный мир» в 1906 году, что «если бы у нас был только один писатель - Андреев и если бы только и существовали что его отклики на этот кошмарный и великий год русской жизни, мы не имели бы права жаловаться на нашу литературу...» ${ }^{2}$

Андреев ждал приближающуюся революцию и нисколько не сомневался в том, что она придет. О пытливости ума писателя и его проницательности в отношении социополитических изменений в России пишет Й. Догнал: «Он как будто способен заглянуть под поверхностные черты происходящего и, сохраняя определенную злободневность, задумывается над самой сущностью, над более глубокими причинами сдвигов в русской общественной жизни» ${ }^{3}$. Будучи другом М. Горького, на раннем этапе своего творчества Андреев не мог

2 NEVEDOMSKIJ, M. P.: Chudožestvo i žizn'. Sovremennyj mir, 19o6, № 12, s. 76.

3 DOHNAL, J.: Koncepcija revoljucii v publicistike Leonida Nikolajeviča Andrejeva. Novaja rusistika, 2014, № 1, s. 56. 
не поддаться влиянию автора «Буревестника», ощущая себя его политическим и идеологическим соратником ${ }^{4}$.

Еще в 1900 году писатель пишет рассказ «В темную даль», который был высоко оценен критикой. М. Горький также с одобрением принял его и отметил появившийся в нем новый для Андреева тип героя, свидетельствующий для него о дальнейшем сближении автора с революционным крылом русского освободительного движения: «Хорош этот Николай, ушедший в темную даль! Он, действительно, орленок, хотя и пощипанный!» ${ }^{5}$ Впоследствии концепция революции излагается Андреевым в 1905-1908 гг. в таких произведениях, как «Губернатор» (1905), «К звездам» (1905), «Так было» (1906), «Царь Голод» (1907) и др.

Революционные идеи Андреева актуализировались к 1917г., когда он попытался разобраться в новой исторической ситуации. Писатель буквально предсказал предполагаемый ход политических и военных событий, ряд революций в странах Европы в записи «Мое предсказание» ${ }^{6}$, датированной 26 августа 1914 г. Будучи еще в России ${ }^{7}$, он восторженно принимает начавшийся буржуазный переворот, входит в редакционный Совет реакционной газеты «Русская воля». 27 февраля 1917г., когда всеобщая политическая стачка переросла в вооруженное восстание и на сторону революции перешла значительная часть армии, Андреев пишет в своем дневнике: «Нынче [...] Один из величайших и радостных дней для России. Какой день!» Но уже последующая запись в дневнике писателя за 2 марта 1917 г. кардинально отличается от предыдущей: «Празник души кончился. Положение очень трудное и тревожное» ${ }^{8}$. А 7 ноября 1917 года Андреев еще с большим волнением высказывается о политических событиях: «Что будет? Жутко и холодно. [...] Слишком много мучений будет и для тела и для души,

4 Несмотря на тесную связь с М. Горьким, уже с 1902 года Л. Н. Андреев начинает чувствовать свою непохожесть на него и во взглядах на жизнь, и в подходе к творчеству, что впоследствии и приводит к разрыву их отношений. В письме к Горькому за 1 июня 1902 г. он пишет: «По нашим писаниям люди со стороны могут принять нас за врагов: ты храбрый, я трус; ты нападаешь на жизнь, я обороняюсь; ты свободный, я раб...» Cм.: ANDREJEV, L. N.: S.O.S.: Dnevnik (1914-1919); Pis'ma (1917-1919); Stat'ji i interv'ju (1919); Vospominanija sovremennikov (1918-1919). Moskva; Sankt-Peterburg: Atheneum; Feniks, 1994, s. 152).

5 Там же, с. 83.

6 «Мое предсказание» - фрагмент из дневника Л. Н. Андреева за 1914 год. Запись переопубликована в качестве приложения к следующей статье. См.: IJEZUITOVA, L. A.: L. N. Andrejev-publicist v kanun revoljucii. Russkaja literatura, 1989, № 3, s. 199-209.

7 В октябре 1917 года Андреев вместе с семьей уезжает на дачу в Ваммельсуу в Финляндию.

8 ANDREJEV, L. N.: S.O.S.: Dnevnik (1914-1919); Pis'ma (1917-1919); Stat'ji i interv'ju (1919); Vospominanija sovremennikov (1918-1919). Moskva; Sankt-Peterburg: Atheneum; Feniks, 1994, s. 30 . 
если победят большевики» ${ }^{9}$. Так, восторженное принятие писателем Первой русской и Февральской революций сменяется его полным разочарованием в последующем большевистском перевороте.

Рассмотрев отношение Андреева к политическим изменениям, остановимся на Первой русской революции и сосредоточим свое внимание на восприятии Андреевым событий 1905 года, а также их отражении в его жизни и рассказе «Губернатор» (1905), созданном писателем на основе реальных событий.

В 1891-1905 гг. пост московского генерал-губернатора занимал Великий князь Сергей Александрович - брат Александра III и дядя Николая II. C 1894 г. он также являлся членом Государственного Совета и близким доверенным лицом и советником своего племянника Николая II, что давало ему огромное влияние. Когда же в январе 1905 года в Петербурге произошло «Кровавое воскресенье», боевая организация партии эсеров вынесла смертный приговор великому князю, так как именно он был одним из тех, кто настоял на вооруженном разгоне шествия. Также на его судьбу повлияла его плохая репутация со времен ходынского происшествия. 4 февраля 1905 года карета Сергея Александровича, выезжая из Кремля, была подорвана бомбой, которую бросил террорист Иван Каляев. Великий князь был убит.

Андреев вовсе не оказался в стороне от данных событий. Проживав и учившись с октября 1893 года в Москве, писатель недолюбливал Сергея Александровича, фамильярно называл его «Сережкой». Однажды вместе со своими товарищами, студентами-собутыльниками, Андреев в нетрезвом состоянии оставил обоз с нечистотами перед домом Сергея Александровича, выражая таким образом свое недовольство властью ${ }^{10}$.

Также в воспоминаниях Б. Савинкова, руководителя боевой организации партии, присутствует следующий эпизод: подготавливая теракт с целью убийства московского губернатора великого князя Сергея Александровича, Савинков, по совету члена организации Ивановской, пришел к Андрееву домой и попросил познакомить его с князем Д. Шаховским, бывавшим в гостях у писателя. Князь знал расписание выездов московского губернатора, и данная информация помогла бы в организации терракта. Ничего не подозревавший Андреев отрекомендовал Савинкова князю и тем самым внес свой вклад в террористический заговор ${ }^{11}$.

Кроме того, еще в 1904 году Леонид Николаевич совместно с другими московскими писателями подписывал гневные обращения к властям, протестуя

9 Там же, с. 32.

10 SKOROCHOD, N. S.: Leonid Andrejev. Moskva: Molodaja Gvardija, 2013.

11 SAVINKOV, B. V.: Vospominanija terrorista. Moskva: VEČE, 2016, s. 53-54. 
против жесткого сценария разгона студенческих демонстраций. А 9 февраля 1905 года, в собственном доме, он был арестован за предоставление квартиры для заседаний ЦК РСДРП и был выпущен после того, как за него внес залог меценат Савва Морозов.

Все эти эпизоды из жизни Андреева показывают, что русская революция с самого начала оказалась для него судьбоносной и, конечно же, была отражена во многих его произведениях.

Не исключением явился и рассказ «Губернатор», написанный в 1905 году. Как утверждают некоторые исследователи, например, Н. С. Скороход, написавшая книгу об Андрееве из серии ЖЗЈ ${ }^{12}$, именно московский губернатор князь Сергей Александрович явился прообразом героя анализируемого нами рассказа «Губернатор». Андреевская история о градоначальнике, который, отдав приказ расстрелять рабочую демонстрацию, узнает, что революционеры вынесли ему смертный приговор, а впоследствии умирает от рук человека из народа, действительно отражает судьбу великого князя. Несмотря на то, что андреевского губернатора зовут Петр Ильич и трудно сказать, в каком именно городе происходят события рассказа, многие сюжетные детали произведения, а также год написания рассказа (1905), действительно позволяет предположить, что он явился реакцией писателя на начало Первой русской революции, а именно на ее ключевое событие - «Кровавое воскресенье», и также на убийство Каляевым московского губернатора.

Но несмотря на то, что Андреев в рассказе «Губернатор» изображает революционные события, они в большей степени оказываются фоном, причиной для внутренних переживаний главного героя, который постепенно приходит к пониманию того, что один лишь его взмах платка привел к расстрелу сорока семи человек, включая женщин и детей. С этого момента начинаются внутренние изменения губернатора Петра Ильича. Отметим, что появление в тексте события, часто неожиданного, заставляющего героя рефлексировать по поводу произошедшего, характерно для творческого метода Андреева. Именно такое построение сюжета выделяет в рассказах Андреева в качестве почти регулярно повторяющейся схемы Й. Догнал. Он называет это «моментом перелома», подразумевая под этим ситуацию, в которой стабилизированная структура психического устройства литературного персонажа (состояние «до») подвергается проверке в состоянии «после» 13 .

12 SKOROCHOD, N. S.: Leonid Andrejev. Moskva: Molodaja Gvardija, 2013.

13 DOHNAL, J.: Povídková Tvorba Leonida Nikolajeviče Andrejeva. Brno: Masarykova univerzita, 1997, s. $44-45$. 
Губернатор, являясь частью бюрократической машины, постепенно проходит сложнейший путь осознания своего бесчеловечного приказа, не являющегося государственной необходимостью. Петр Ильич рассуждает, что вроде бы поступил согласно своей должности, так как в государстве должен быть порядок. Кроме того, его поступок одобрили в Петербурге и даже теперь «восхищаются мужеством и твердостью Петра Ильича» ${ }^{14}$. Но вид мертвых женщин и детей, убитых по его приказу, понимание того, что «...они свои, русские», такие же люди, как и он, заставляют его постоянно вспоминать момент взмаха его платка, последующие выстрелы и кровь.

Вдруг Петр Ильич начинает замечать за собой, что его внешнее поведение не характеризует и никогда не характеризовало его как того человека, которым он является, а оказывается лишь проявлением роли, которую он выполняет в обществе: «И чувствует, что, пока он думал, он был просто человек, как всякий другой, Петр Ильич, а с первым же звуком голоса, с первым же жестом он сразу стал губернатором...» ${ }^{15}$, «... он сердито зашагал прямыми твердыми шагами: „Так ходят губернаторы. Так ходят губернаторы“» ${ }^{16}$. Подобное он чувствует и в казенной квартире, где он проживает, вся ее обстановка говорит Петру Ильичу о том, что здесь когда-то тоже жили губернаторы, которые, возможно, также стреляли в простых людей, но не испытывали чувства вины, ведь они «исполняли свой долг» перед отечеством. Однако Петр Ильич, отличающийся от других высокопоставленных лиц, понимает, что совершил антигуманный поступок, поступок негодяя, и он сам опровергает довод о государственной необходимости этого. «Только какая же это государственная необходимость стрелять в голодных? Государственная необходимость - кормить голодных, а не стрелять» ${ }^{17}$. Происходит разрушение «человека-должности», заложника политического аппарата, и высвобождение в Петре Ильиче человеческого, стираются границы между его ролью губернатора и ролью человека из народа.

Для Петра Ильича становится совсем очевидным то, что за отданный им приказ расстрелять людей он сам понесет наказание, так как все люди, какую бы позицию они не занимали в обществе, равны перед законом кровной мести, существовавшим с древности. Губернатор упоминает о нем в разговоре со своим сыном: «Вы новые, вы академики, вы ни во что не верите, а я верю в старый закон: кровь за кровь». С этого момента в тексте начинают появляться

14 ANDREJEV, L. N.: Polnoje sobranije romanov, povestej i rasskazov v odnom tome. Moskva: AL'FA-KNIGA, 2017, s. 937.

15 Там же, с. 938.

16 Там же, с. 939.

17 Там же, с. 947. 
упоминания об этом «вселенском законе» ${ }^{18}$, он становится будто осязаемым, отдельным персонажем рассказа, который наблюдает за происходящим и руководит им: «...когда живые тревожно спали, а убитые все в том же удивительном порядке, ногою к ноге, спокойно лежали в пожарном сарае, над городом пронесся кто-то темный и весь его осенил своими черными крыльями» ${ }^{19}$. Неслучайно изначально Андреев дал другое название своему рассказу - «Бог отмщения» - подчеркивая тем самым важность в рассказе «образа Закона Мстителя» 20 .

В произведении также упоминается о тех, кто разбудил этот старый закон - о женщинах. «Обычно жалостливые и боящиеся крови, в этом случае обнаруживали странную жестокость и непобедимое упрямство: почти все они стояли за смерть» губернатора ${ }^{21}$. «Они не рассуждали, не доказывали, они просто ждали - и в ожидание свое вносили весь пламень непоколебимой веры, всю тоску своей несчастной жизни, всю жестокость обнищавшей, голодной, задушенной мысли» ${ }^{22}$. Причиной этому было то, что из-за приказа Петра Ильича вместе со взрослыми расстреляли и детей, отчего губернатор получил в народе страшное прозвище: «Убийца детей» ${ }^{23}$.

Приближающееся над губернатором возмездие становится очевидным и для самого Петра Ильича, который впервые почувствовал «бесповоротность случившегося» 24 в момент осмотра раненных после расстрела рабочих, отводивших от него свои взгляды, и для окружения Петра Ильича. Все вдруг стали очень любезны по отношению к нему, пытались приободрить, поддерживали отданный губернатором приказ и обращались с ним так, как будто он «неизлечимо больной человек, которому вредно всякое усилие» ${ }^{25}$. Но его сын, офицер, представитель молодого поколения, с которым Петр Ильич «давно уже [...] разошелся во взглядах» ${ }^{26}$, не понимал беспокойства отца по поводу произошедшего, видя в его рассуждениях «что-то грубое, варварское, атавистическое». Алексей Петрович думает о нем: «Однако плохой ты губернатор, хотя тебя и похвалили» ${ }^{27}$. Андреев показывает разницу между

\footnotetext{
18 Там же, с. 947.

19 Там же, с. 950.

20 Там же, с. 968.

21 Там же, с. 951.

22 Там же, с. 953.

23 Там же, с. 950.

24 Там же, с. 936.

25 Там же, с. 937.

26 Там же, с. 943.

27 Там же, с. 944.
} 
сыном, строго придерживающимся своего положения в обществе, и отцом, не желающим выполнять роль губернатора, если она предполагает убийство таких же, как и он. Жена Петра Ильича беспокоится за состояние мужа, но и она не воспринимает всерьез слухи о его возможном убийстве.

Не найдя понимания среди семьи, Петр Ильич заводит разговор с человеком из народа, его рабочим Егором, который мог бы, по мнению губернатора, подтвердить или опровергнуть очевидность его предстоящей смерти. Старик без сомнения говорит, что Петра Ильича убьют «по-нашему, по-деревенскому» ${ }^{28}$, намекая на все тот же «древний седой закон, смерть карающий смертью» ${ }^{29}$, а также указывая на то, что воля народа обладает большой силой.

Герой, окончательно убедившись в неотвратимости смерти, готовится к народному возмездию. Большую часть всего рассказа занимает именно процесс осознания губернатором приближающегося конца. Петр Ильич не пытается скрыться от народа, а, наоборот, старается быть ближе к нему: без опаски гуляет по даче, общается с людьми из деревни, интересуется их бытом. Поближе познакомившись с жизнью рабочих и крестьян, герой еще больше начинает ощущать себя «негодяем» ${ }^{30}$, ведь когда-то давно он сам испытывал с женой нужду, носил «оловянные», а «не золотые кольца» ${ }^{31}$, т. е. ничем не отличался от простых людей, и теперь он понял, что на самом деле лишь его общественное положение разделяет его с ними.

Народ, в свою очередь, стремится высказать губернатору свое отношение к нему, делая это посредством писем, приходящих Петру Ильичу. Герой прочитывает их все, так как ему становится важно народное мнение. Эти письма принадлежат разным адресантам, и в них дана неоднозначная оценка личности губернатора. «В общем, при всем внешнем различии в языке и степени грамотности, содержание писем было утомительно однообразно: друзья предупреждали, враги грозили, и выходило что-то вроде коротких и бездоказательных „да“ и „нет“. К словам: „убийца“, с одной стороны, и „доблестный защитник порядка“» 32 .

На фоне всех полученных губернатором писем выделяется одно, подписанное словом - «Рабочий» ${ }^{33}$. По манере и стилю написания становится ясно, что человек, отправивший его, образован и является одним из представителей

\footnotetext{
28 Там же, с. 949.

29 Там же, с. 951.

30 Там же, с. 950.

31 Там же, с. 948.

32 Там же, с. 957.

33 Там же, с. 958.
} 
прогрессивной рабочей молодежи (сравнимый с Павлом Власовым из романа М. Горького «Мать»). Данное письмо примечательно тем, что, по сути, является единственным местом в рассказе, в котором дана оценка приближающейся революции. Его автор подчеркивает силу и «пробуждение» народных масс: «Народ просыпается! Пока он только еще во сне ворочается, а у вашего дома подпорки уже трещат, а вы погодите, как он совсем проснется!» [959-960] Он также вдается в размышления о том, что революция является в большей степени «пропагандой идей» ${ }^{34}$ и победить можно будет только «головой, а не руками, потому что на голову подлецы слабы» ${ }^{35}$. Именно поэтому, по мнению молодого человека, рабочих заставляют работать на заводах одинадцать часов, ведь при таком раскладе у людей просто не будет оставаться времени и они не «станут умнее хозяев» ${ }^{36}$.

Но молодой человек не только высказывает в письме свое отношение к складывающейся политической ситуации, в первую очередь, он выражает свое сочувствие Петру Ильичу, называет его честным: «Скажу даже, что вы вообще честный человек - вообще честный человек - вообще честный человек - и сами не обидите и курицы, если вам не прикажут ее обидеть» ${ }^{37}$.

В этом и заключается трагедия Петра Ильича, который не был ни глупым, ни злым человеком, но его зависимость от более высоких чинов, своего общественного положения, попытка соответствовать отведенной ему роли привели к тому, что он совершил ошибку, отдал жестокий приказ, который повлек за собой гнев народа. Несмотря на признание губернатором своей вины, спустя несколько недель один человек из народа застрелил его из револьвера. Произошедшее ни для кого не становится неожиданностью, потому что никто не сомневался в том, что кровный закон, который существовал еще со времен первобытного общества, сработает: «Никто еще не говорил, а все уже знали: как будто в эту ночь, когда живые тревожно спали [...] над городом пронесся кто-то темный и весь его осенил своими черными крыльями» ${ }^{38}$.

Таким образом, Андреев в рассказе «Губернатор», хоть и реагируя на политические события, которые были злободневны, волновали общество и самого писателя, освещает в большей степени внутренние метания отдельного человека, его способность или неспособность в проявлении сострадания и человечности, руководствуясь не логикой власти, не ролью, которую

\footnotetext{
34 Там же, с. 958.

35 Там же, с. 958.

36 Там же, с. 958.

37 Там же, с. 959.

38 Там же, с. 930.
} 
он выполняет в обществе, а общечеловеческими моральными ценностями. Историческое событие оказывается лишь причиной, переломным моментом, после которого герой начинает меняться внутренне. Андреев как будто хочет сказать читателю, что в первую очередь в мире все работает в соответствие со старыми первобытными человеческими законами, перед которыми все равны, неважно, какие события происходят в истории, будь то революция, война или нечто другое. Так, Андреев переходит от частного к общечеловеческому уровню, от рассказа о губернаторе, от конкретных исторических событий к рассуждениям о первозданном, природном устройстве мира и человеческой сущности.

\section{Литература:}

ANDREJEV, L. N.: S.O.S.: Dnevnik (1914-1919); Pis'ma (1917-1919); Stat'ji i interv'ju (1919); Vospominanija sovremennikov (1918-1919). Moskva; Sankt-Peterburg: Atheneum; Feniks, 1994, 598 s. ISBN 5-85042-042-8.

ANDREJEV, L. N.: Polnoje sobranije romanov, povestej i rasskazov vodnom tome. Moskva: AL'FA-KNIGA, 2017, s. 934-968. ISBN 978-5-9922-2560-0.

DOHNAL, J.: Koncepcija revoljucii v publicistike Leonida Nikolajeviča Andrejeva. Novaja rusistika, 2014, № 1, s. 55-63. ISSN 1803-4950.

DOHNAL, J.: Povídková Tvorba Leonida Nikolajeviče Andrejeva. Brno: Masarykova univerzita, 1997, $134 \mathrm{~s}$. ISBN 80-210-1605-1.

IJEZUITOVA, L. A.: L. N. Andrejev-publicist v kanun revoljucii. Russkaja literatura, 1989, № 3, s. 199-209. ISSN 0131-6095.

NEVEDOMSKIJ, M. P.: Chudožestvo i žizn’. Sovremennyj mir, 1906, № 12, s. 70-83. ISBN 5-289-01128-5.

SAVINKOV, B. V.: Vospominanija terrorista. Moskva: VEČE, 2016, $490 \mathrm{~s}$.

SKOROCHOD, N. S.: Leonid Andrejev. Moskva: Molodaja Gvardija, 2013, 430 s. ISBN: 978-5-235-03518-8.

\section{About the author Iuliia Dmitrieva Masaryk University Brno, Faculty of Arts, Department of Slavonic Studies, Brno, Czech Republic gallows.july@mail.ru https://orcid.org/0000-0002-2081-2132}

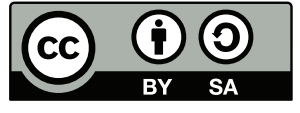

This work can be used in accordance with the Creative Commons BY-SA 4.0 International license terms and conditions (<https://creativecommons.org/licenses/by-sa/4.0/legalcode>). This does not apply to works or elements (such as images or photographs) that are used in the work under a contractual license or exception or limitation to relevant rights. 